\title{
ضمانات المكلف بالضريبة اثناء التحقيقات الجبائية
}

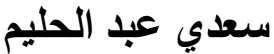

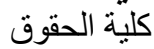

جامعة الإخوة منتوري - قسنطينة

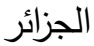

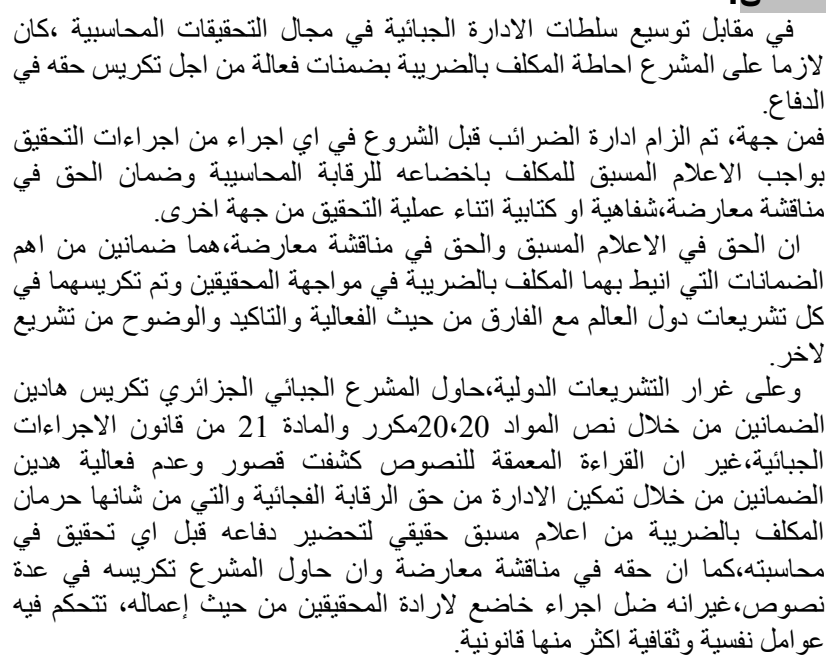

\section{Abstract:}

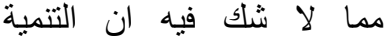
In return for verification's authorities recognised at administration. The taxpayer has been provided by the legislator set of rights and guarantees in order to organise its defence. One part, the taxpayer must be notified about verification before it began. The Other part, the taxpayer must be able to discuss with the administration the regularity of its tax situation and the validity of verification's operation.

Both these Rights, the right of information and contradiction's right were devoted in all or substantially in tax systems. However, their reach varies from one country to another. algeria in particularly, even if the right of information is devoted through articles 20-20bis and article21 from Fiscal Procedure Code. Its reach stays only limited for thorough verification and never divert to surprise effect of verification. Concerning contradiction's right; even if "dialogue culture" is far to be shared in Tunisia, legislator seems that it devoted this right through several provisions in Fiscal Procedure Code. But sites inspection proved that this right stays hypothetic. 


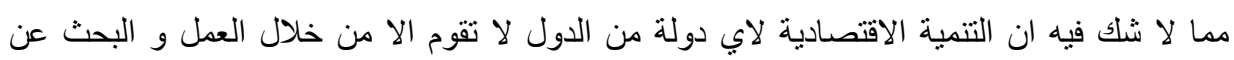

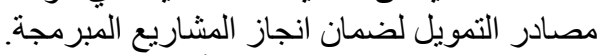

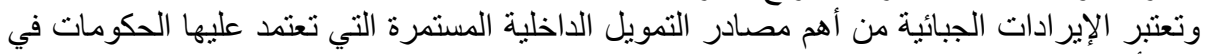

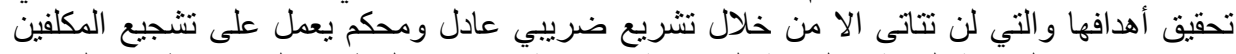

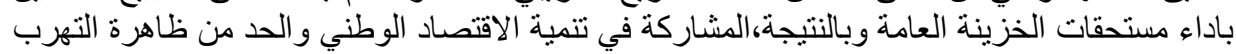

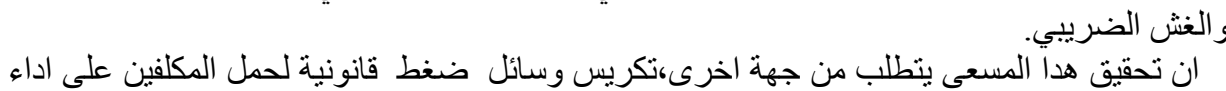

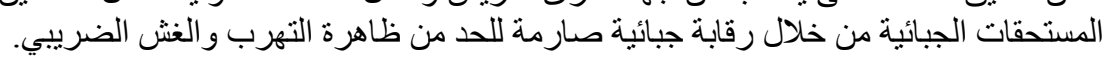

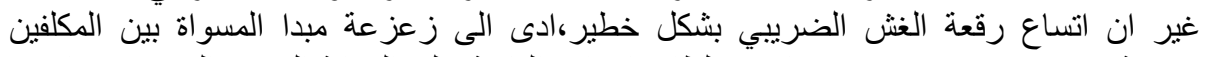

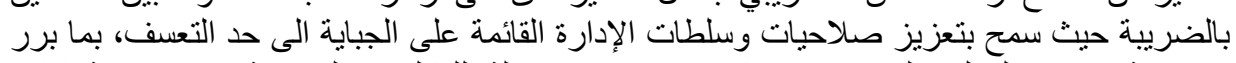
من جهة اخرى العمل على تعزيز وتكريس ضمنات التات فعالة للمكلفين بالضريبة في مواجهة ادارة

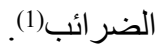

وفي الجز ائر، و على الرغم من الإصلاحات المالية المتخذة منذ عام 1992وما صحبها من تسهيلات

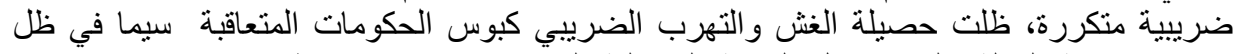

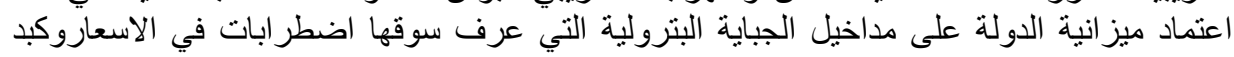

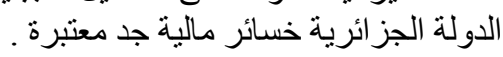

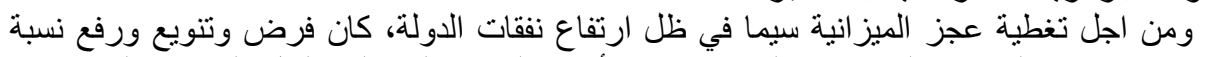

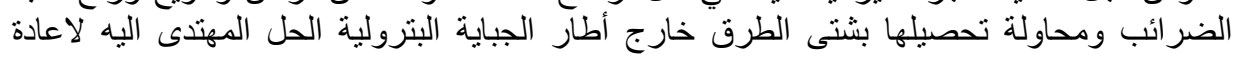

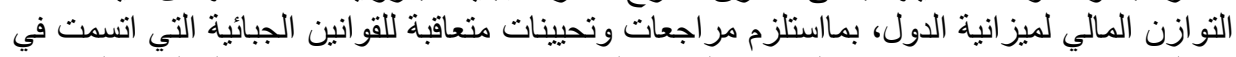

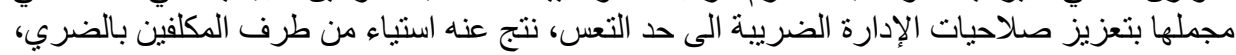

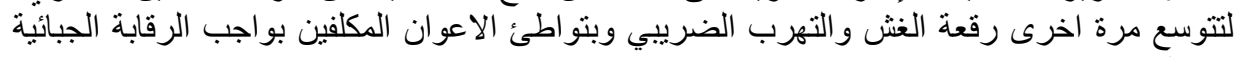

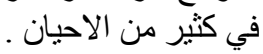

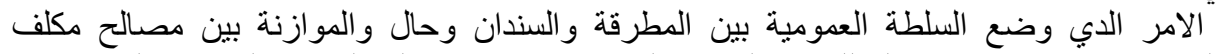

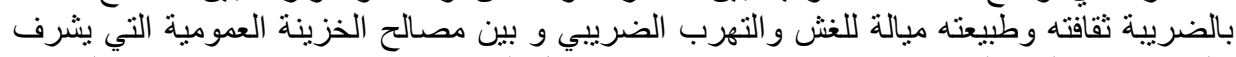
عليها جهاز مكلف بالجباية فقد صفة وطبيعة الادارة وتحول الى المبر اطور من حيث تفكيره و عمله سيما لئه في مجال الرقابة الجبائية.

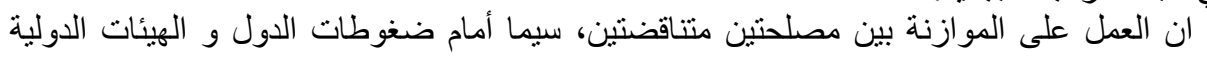

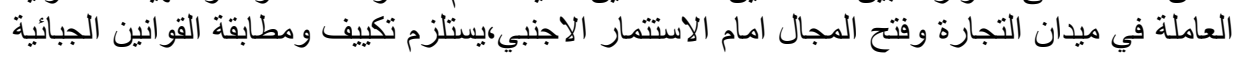

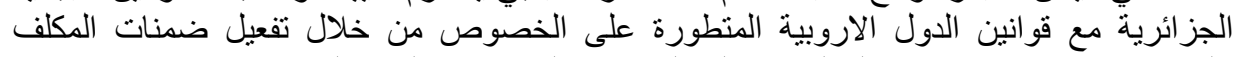

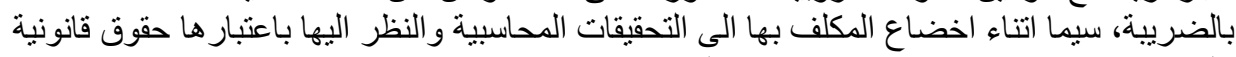

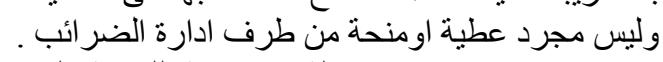

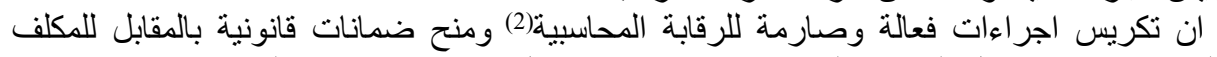

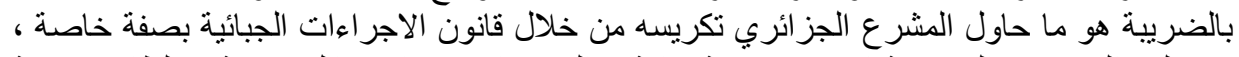

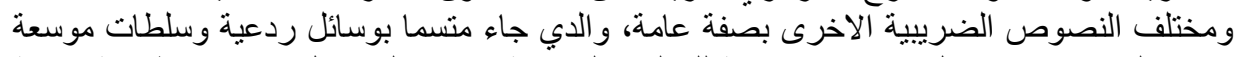

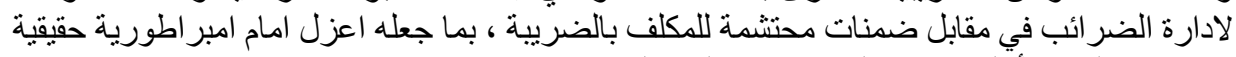

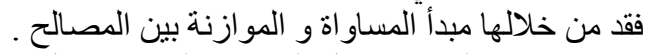
و هو الامر الدي سنحاول الوقوف عليه من خلال حق المكلف في الاعلام ومناقتشة معارضة، كل دللك

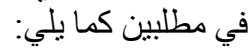
المطب الاول: ضمان الإعلام

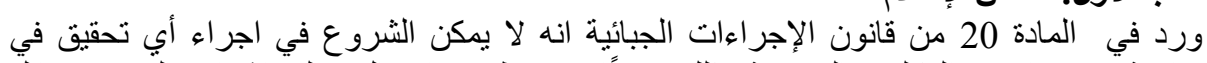

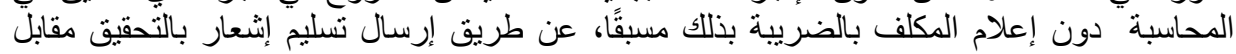




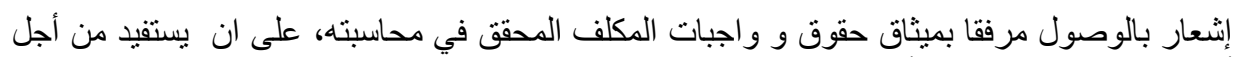

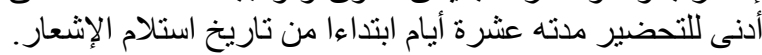

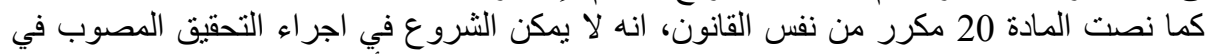

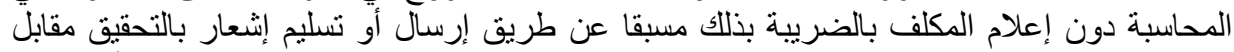

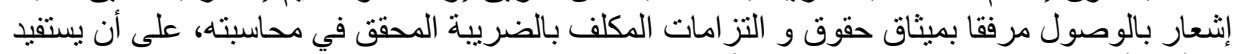

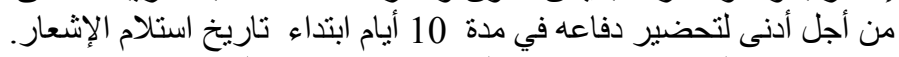

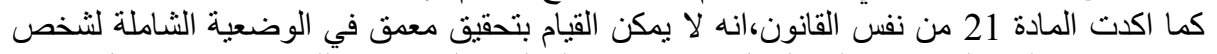

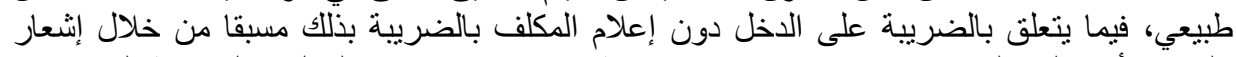

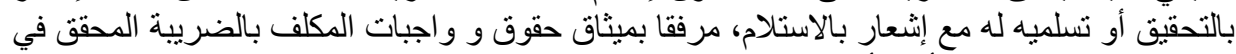

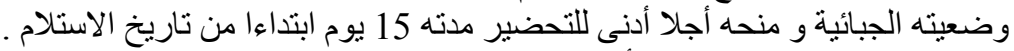

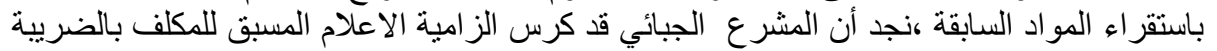

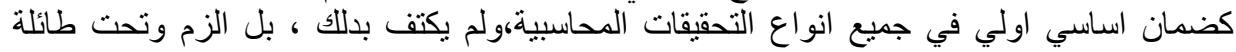

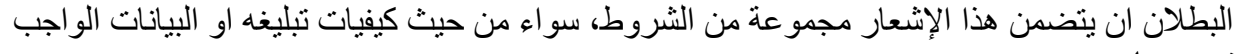

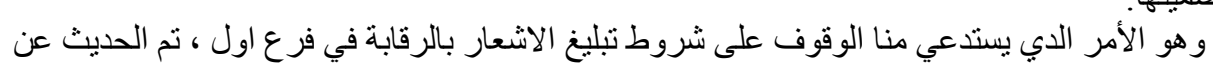

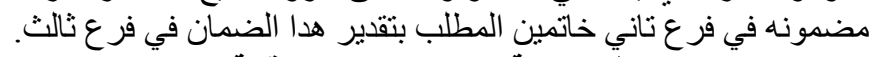

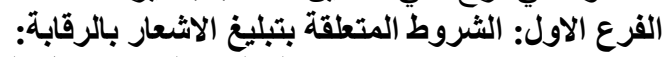

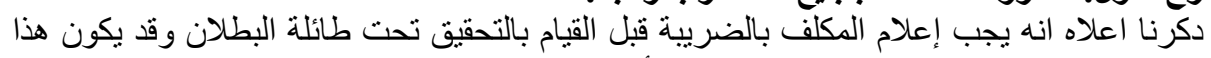

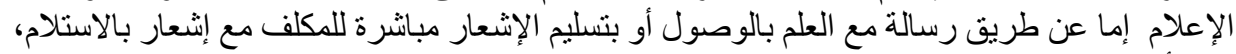

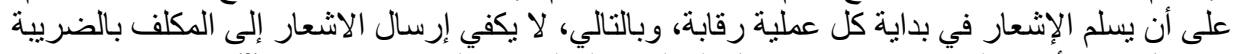

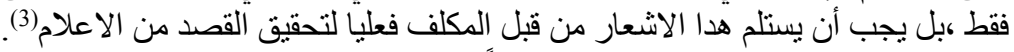

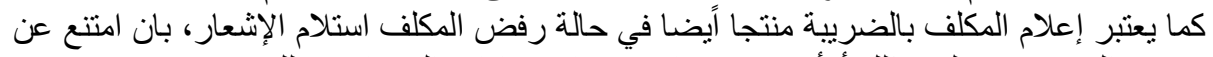

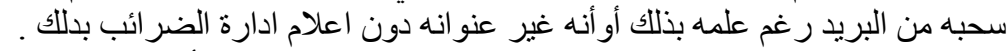

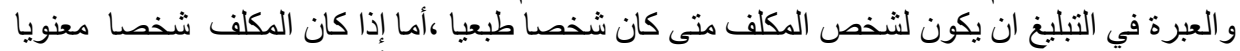

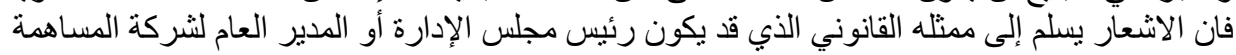

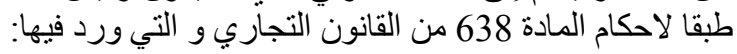

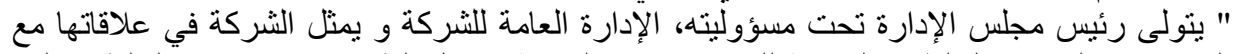

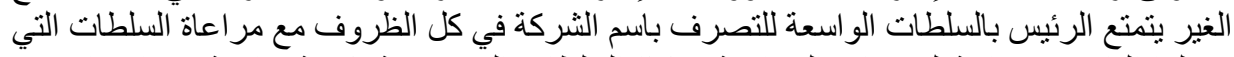

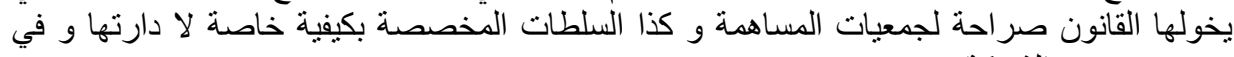

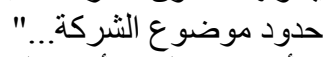

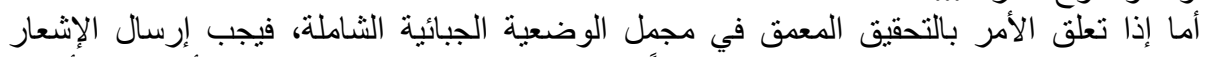

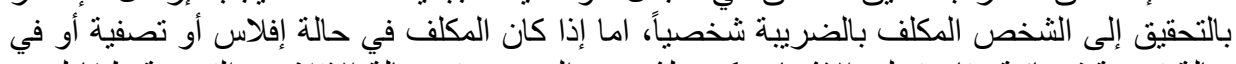

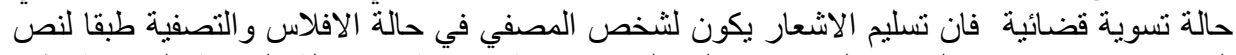

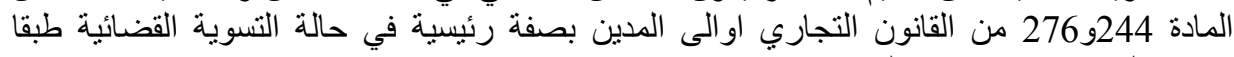

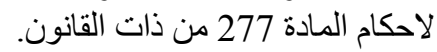

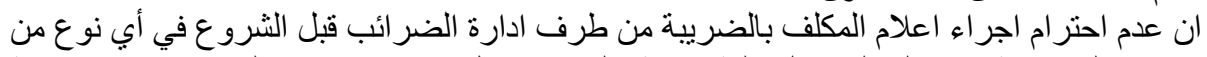

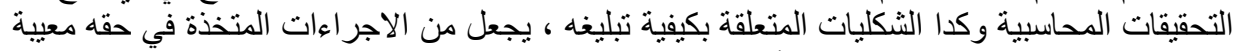

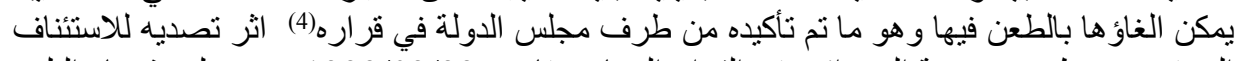

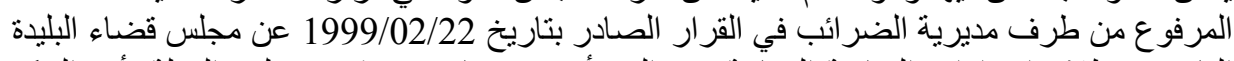

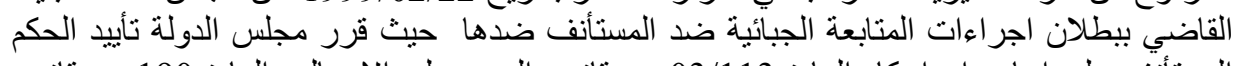

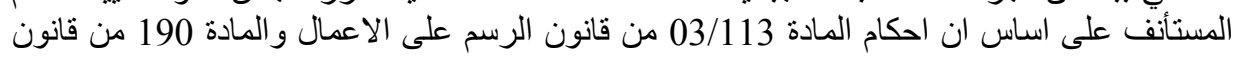
الضر ائب المباشرة تلزمان المحققين بإثعار المكلف بالضريبة بإجراءات الترات التحقيق تحت طائلة البطلان 
غير ان هدا الاجراء لم به المحققون بما يؤدي الى بطلان اجراءات التحقيق التي قانت بها ادارة

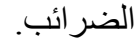

هدا عن اجر اءات تبليغ الاشعار بالاعلام فمادا عن مضمونه؟.

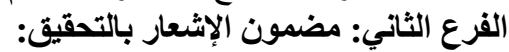

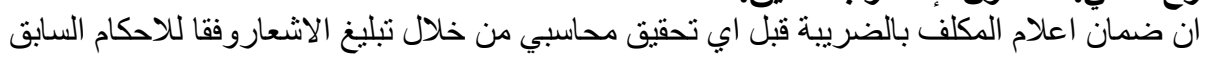

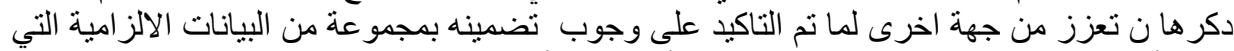

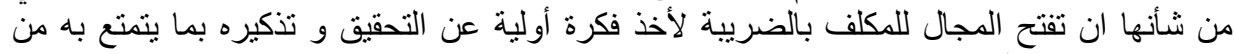

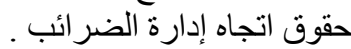

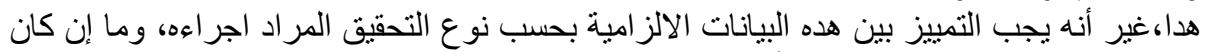

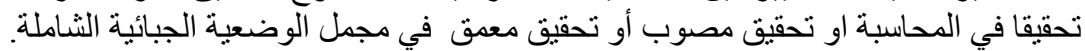

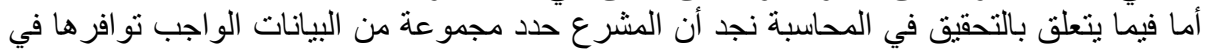

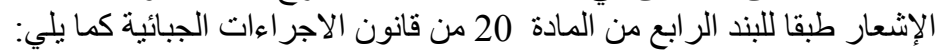

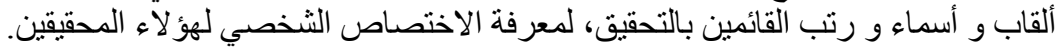

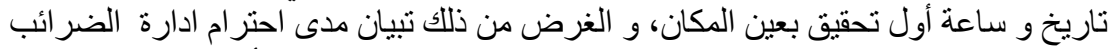

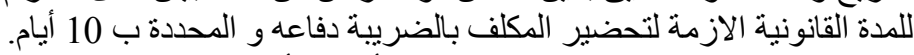

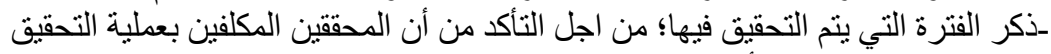

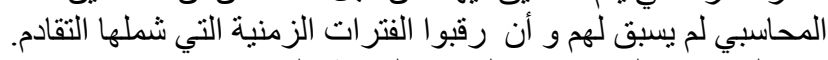
ذكر الحقوق و الضر ائب و الرسوم المعنية بالتحقيق.

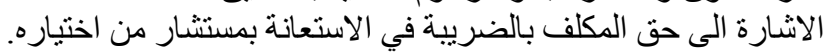

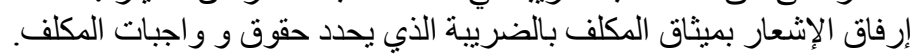

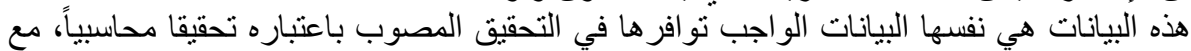

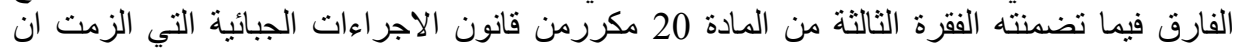

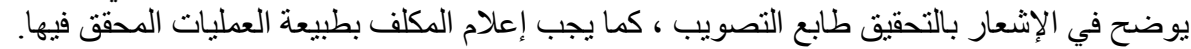

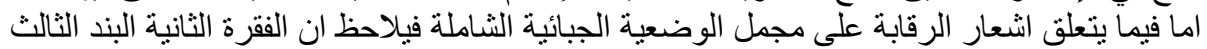

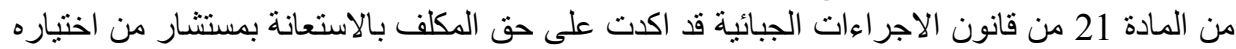

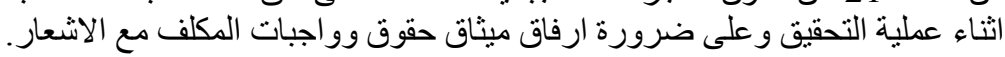

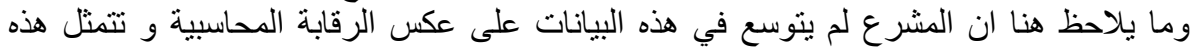

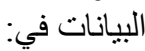
تبيان الددة التي يتم التحقيق فيها، والمتعلق بالسنوات الخاضعة للفحص والإشارة إلى حق المكلف بالضريبة في الآستعانة بمستشار أثناء عملية التحقيق.

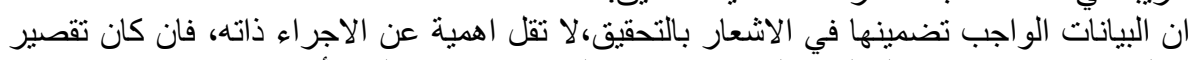

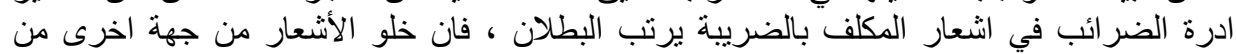

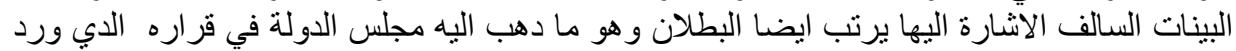

" وحيث انه بالرجوع الى اوراق الملف و الى تصريحات المستأنف عليه، يتضح ان الثركة المستأنف

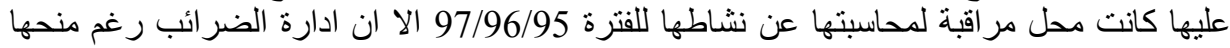

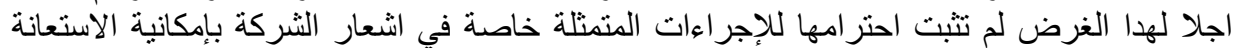

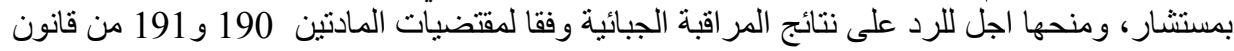

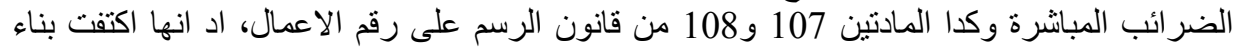

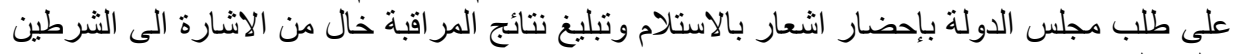

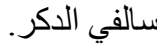


وحيث ان خرق المستأفف عليها للإجراءات المذكورة والتي تعتبر جوهرية ، تعرض عملية المراقبة

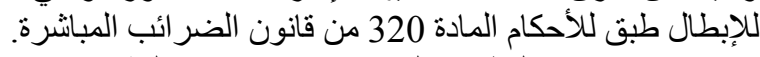

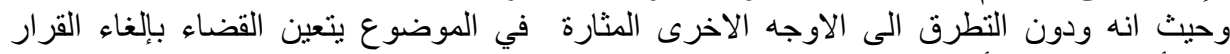

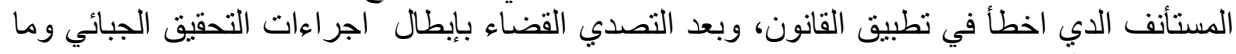

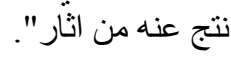

الفرع الثالث: تقدير الضمان

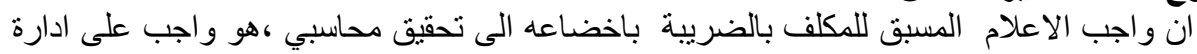

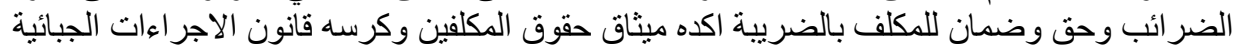

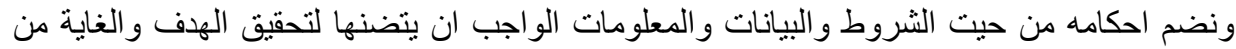

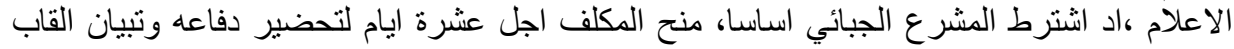

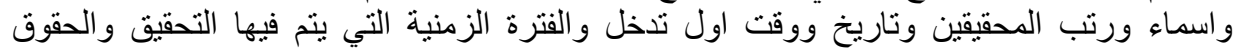

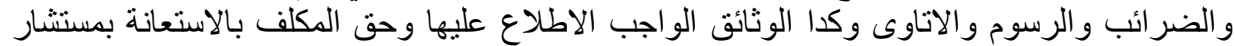

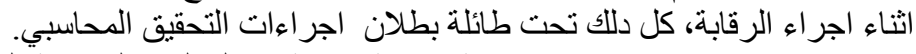

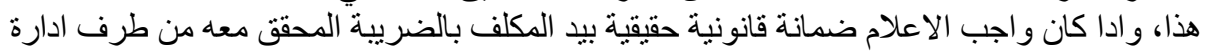

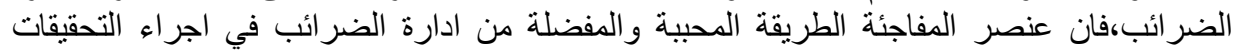

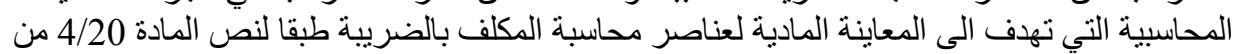

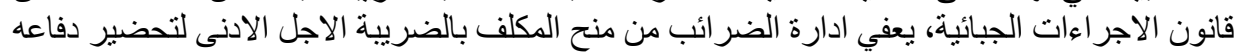

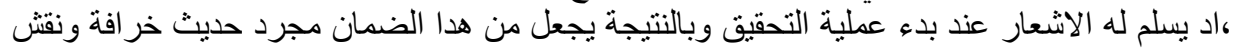

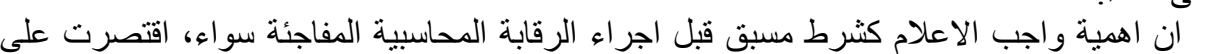
على الماء.

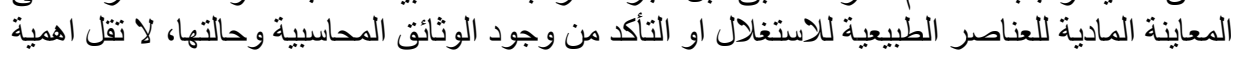

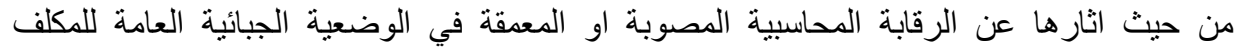
بالضريبة ودلك لسببين اثثين:

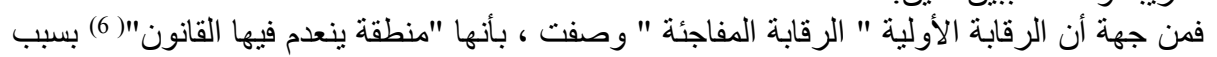

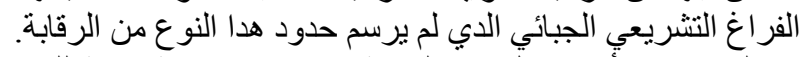

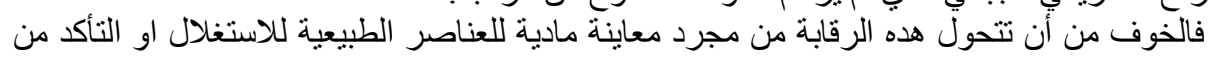

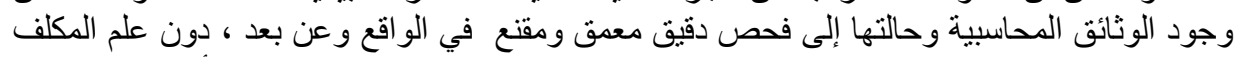

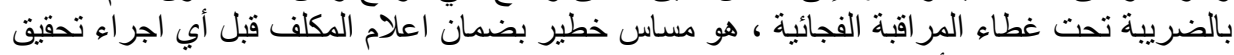

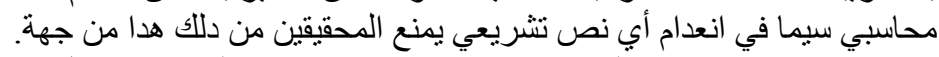

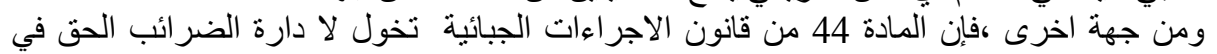

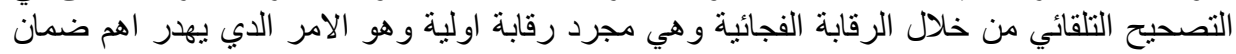

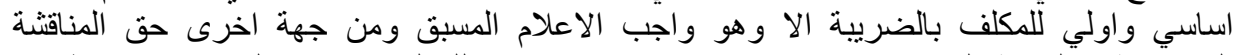

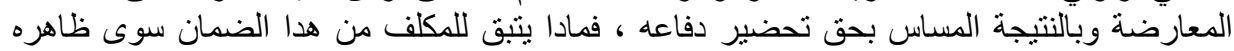

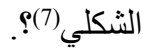

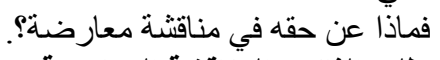

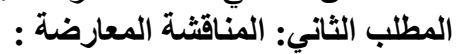
يعتبر الحق في الدفاع بالنسبة للمكلف بالضريبة الضمان العام الدي انيط به اثناء التحقيقات في وضعيته المحاسبية. هذا الضمان وان تم تجسيده من خلال الحق في الاعلام قبل اي اجر اء تحقئ تحقيق -بصفة محتشمة كما راينا ـفانه ومن جهة تانية يتجلى بوضوح من خلال مبدا او حق أخر كرسته كافة التشريعات الجبائية 
على درجات بطبيعة الحال و الامر يتعلق بالحق في مناقثة مناقضة بنوعيها ، شفاهية اومكتوبة وهو

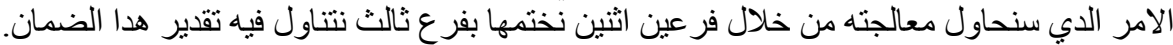

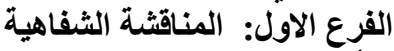

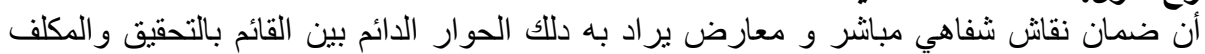

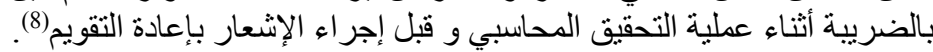

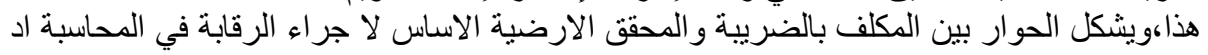

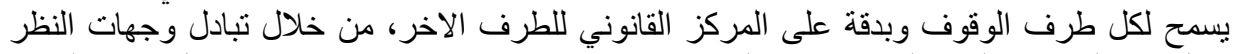

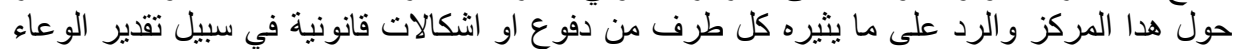

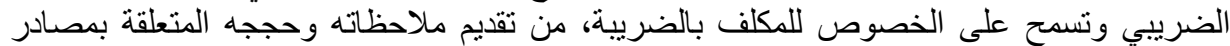
دخله للمحققين.

ويعتبر ضمان المناقتشة الثفاهية المعارضة واقعة مادية يقع عبئ اثباتها على المكلف بالضريبة بان يثبت ان المحقق رفض اي مناقتة معه اثناء التحقيق المحاسبي (9).

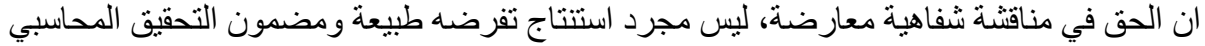

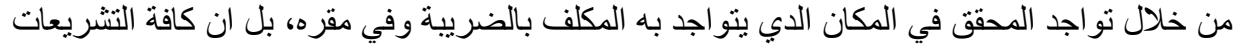

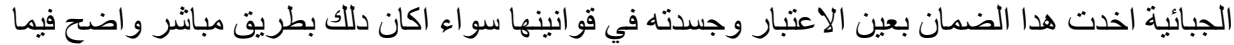

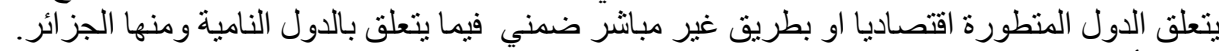

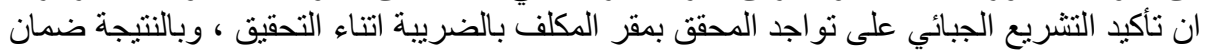

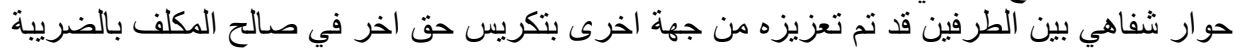

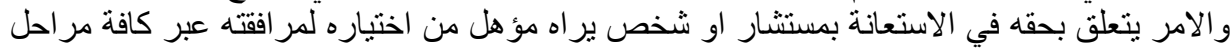

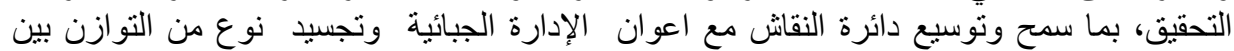

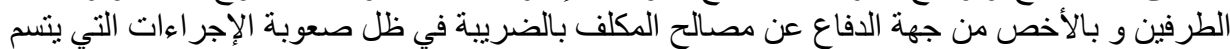

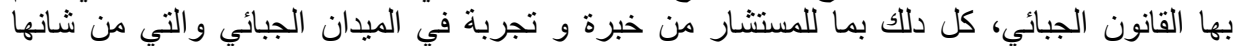

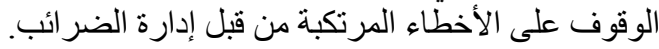

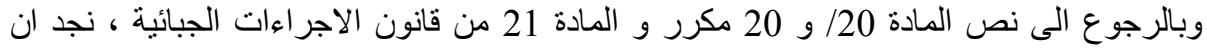

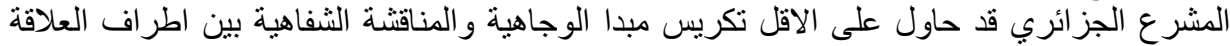

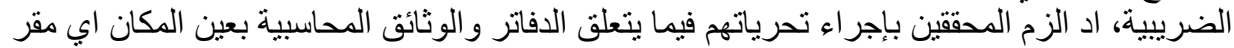

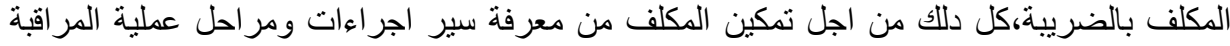
و التعديلات المجار اة.

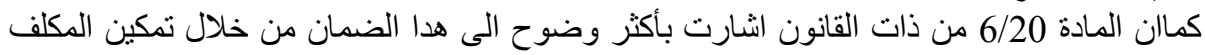

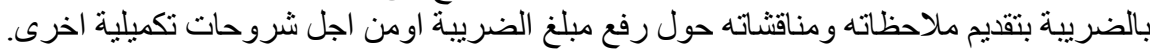

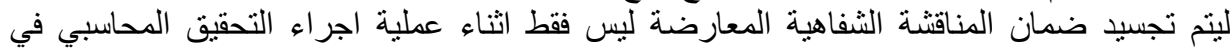

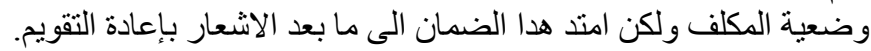
الفرع الثاني:المناقشة الكنابة الكتابية

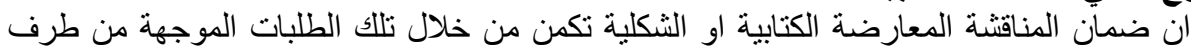

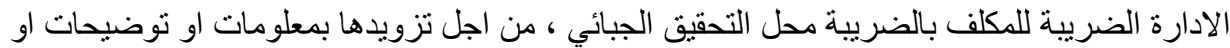

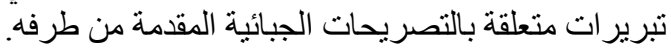

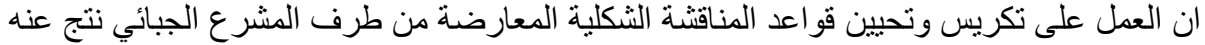

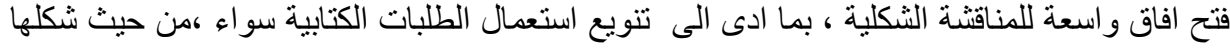
او مضمونها. ومن اهم هده الطلبات الكتابية المستعملة من طرف ادارة الضر ائب اثناء التحقيقات الجبائية:

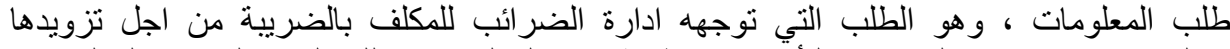
بمعلومات تمكنها من الوقوف والتأكد من مطابقة هده المعلومات وتلاتك التي ادلى بها المكلف في تلفي 
تصريحاته الجبائية ،كل دلك من اجل رفع الغموض واللبس حول نقاط معينة تضمنتها تصريحات

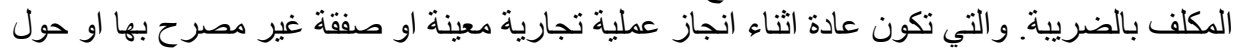

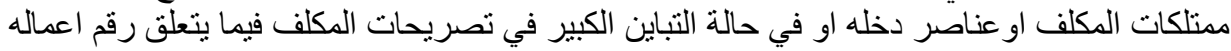

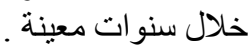

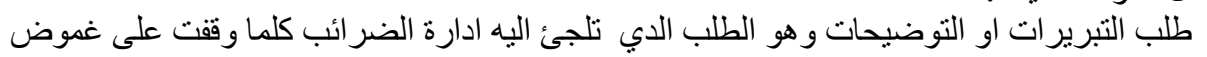

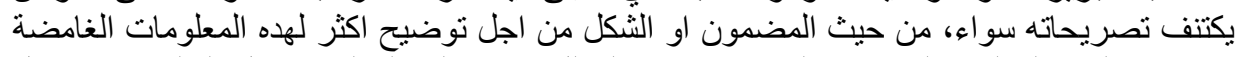

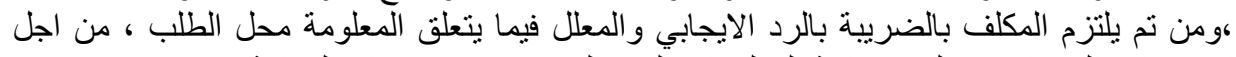

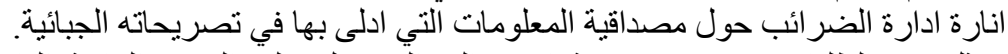

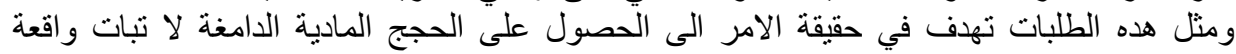

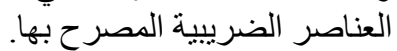
مما سبق، يتضح لنا جليا الفرق بين طلب التبرير التبرات أو التوضيحات وطلب المعلومات، فطلب

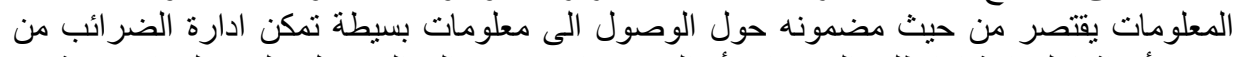

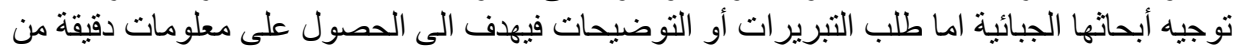

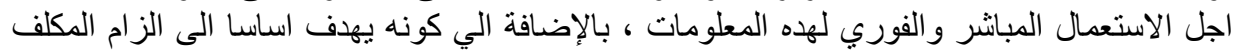

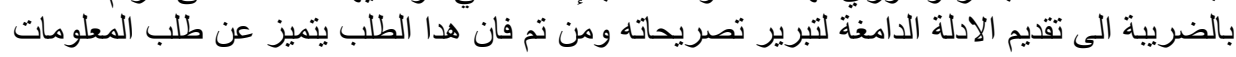

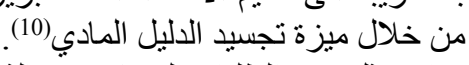

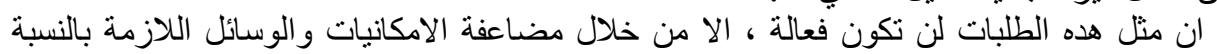

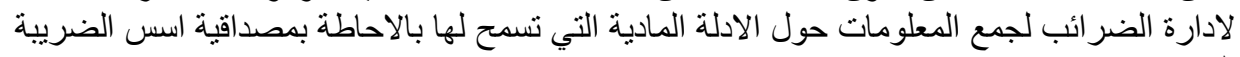

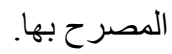

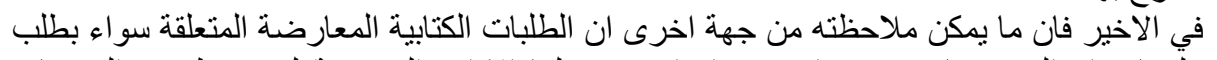

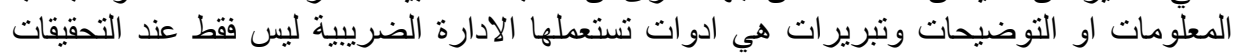

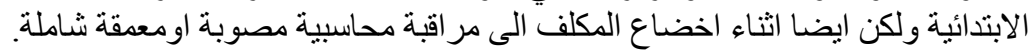

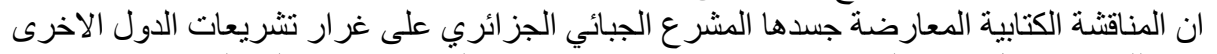

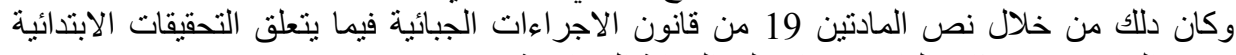

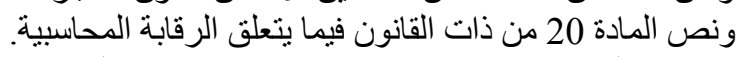

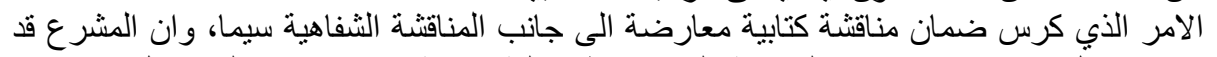

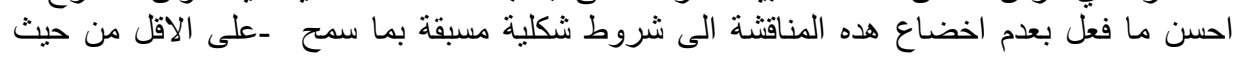

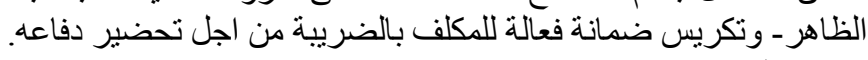
الفرع الثالث: تقدير الضمان

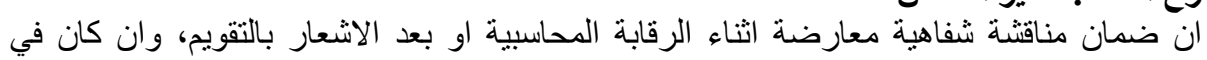

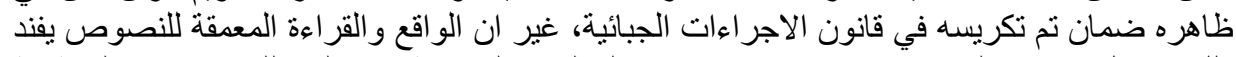

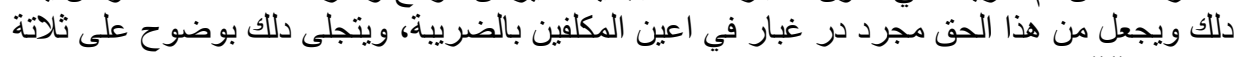
مستو يات(11). فعلى المستوى الاول فإن الحق في مناقثة شفاهية معارضة الثناء التحقيق في محاسبة المكلف

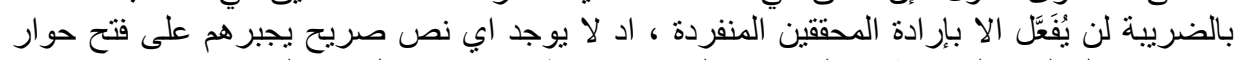

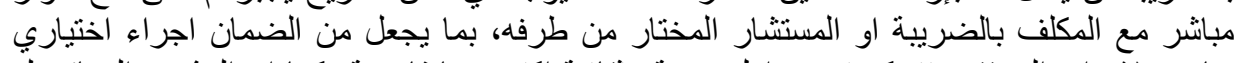

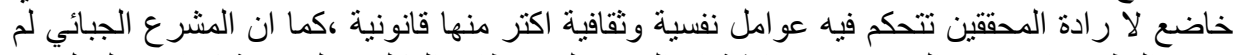

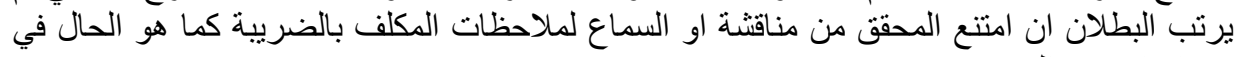

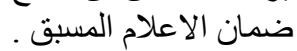

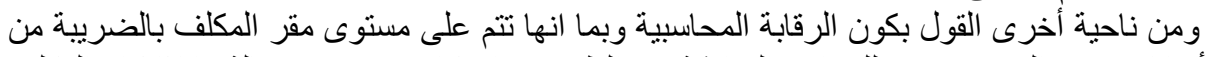

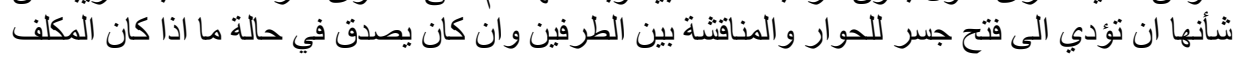

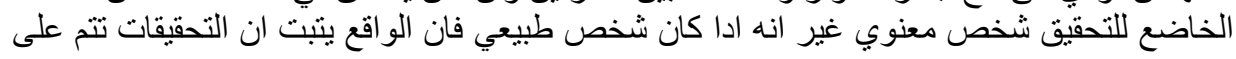


مستوى مكاتب ادارة الضر ائب، بما يجعل من فرصة مناقثة وجاهية شفاهية بين الطرفين ضئيلة ان لم نقل منعدمة.

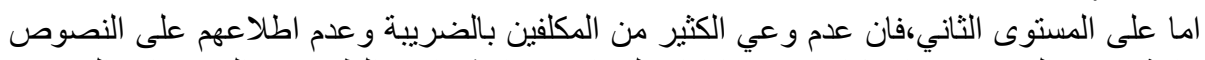

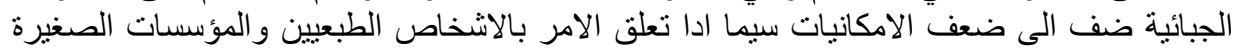

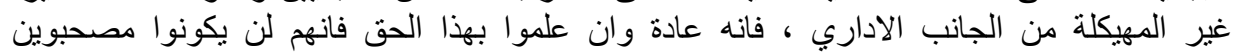

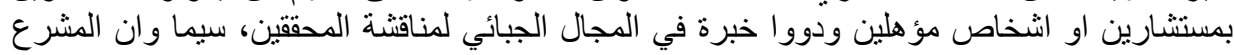

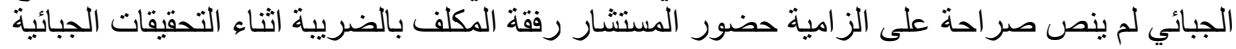

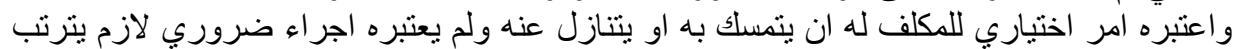
عليه البطلان (12).

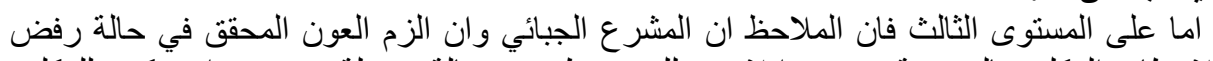

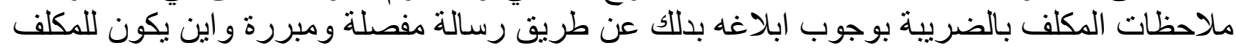

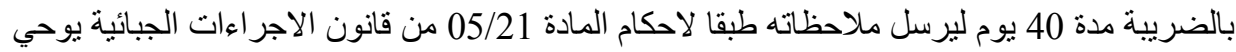

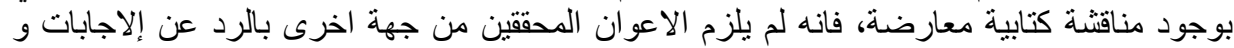

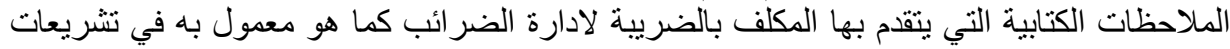

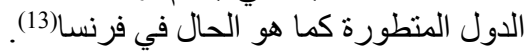
بما يضعف هدا الضمان ويزعزع الضول الضمان الاساس الدي انيط به المكلف بالضريبة الاو هو الحق في الدفاع.

الخـاتـمةة:

ادا كان الهدف من احاطة ادارة الضرائب بسلطات و اسعة من اجل ممارسة مهامها الموكلة لها في

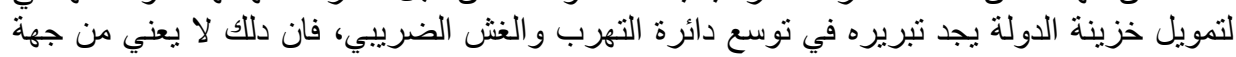

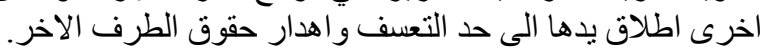

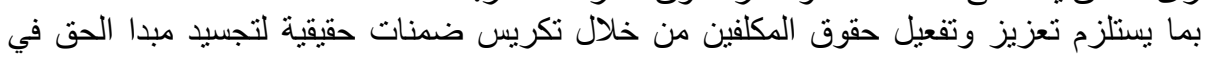

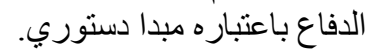

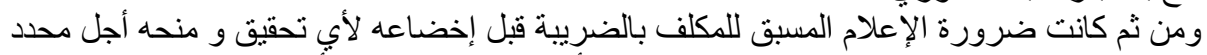

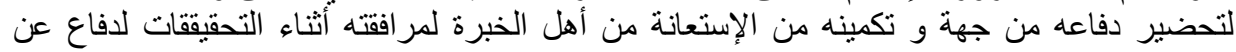

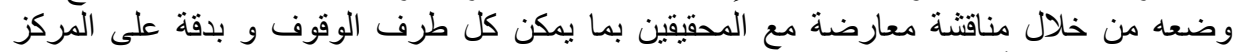

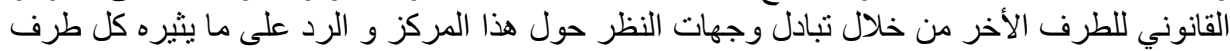

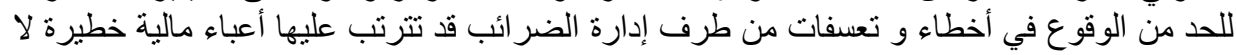

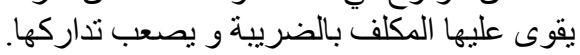

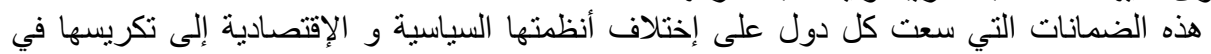

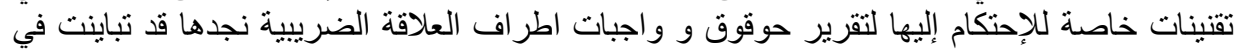

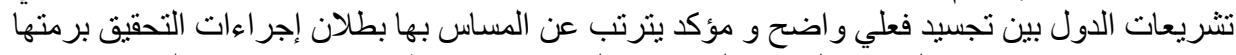

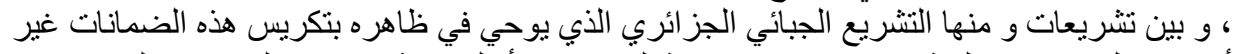

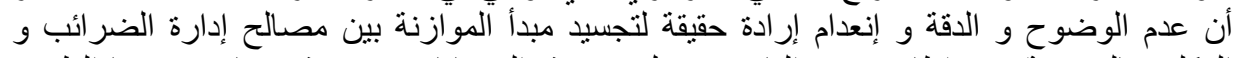

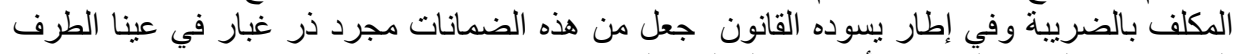

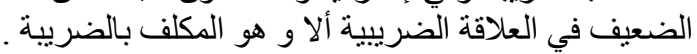

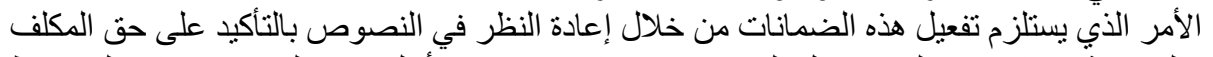

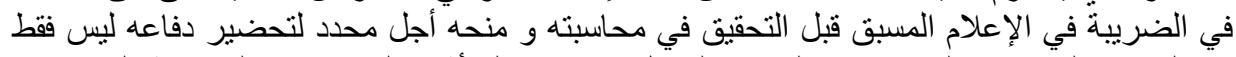

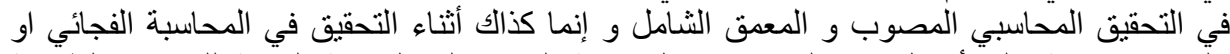
بالتص صراحة على أن التحقيق الفجائي في المحاسبة الرامي إلى المعاينة المأدية للعناصر الطبية الثيعية 
للإستغلال لا يمكن أن يتحول في أي حال من الاحوال إلى تحقيق معمق إلا بعد إثعار المكلف بالضريبة

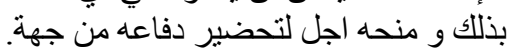

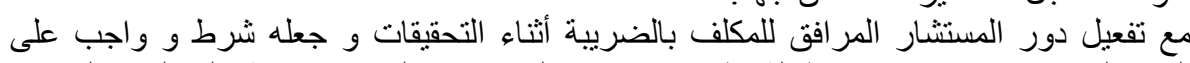

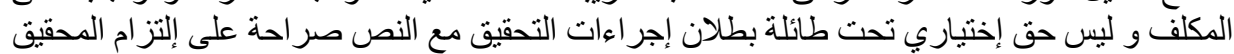

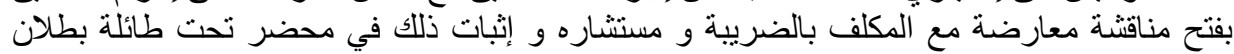
إجراءات التحقيق وكذا إلز ام المحقيق بالرد على ملاحظات المكلف بالضريبة فيما يتعلق إثعاره بإعادة

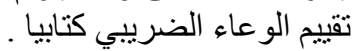

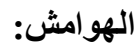

1- G.AMENDEE-MANESME: principes et pratique du droit fiscal des affaires Economica.paris.1990.p.47.

2- ان التحقيق في المحاسبة يقصد منه "مجموعة من التقنيات والتعليمات الهدف منها مراقبة

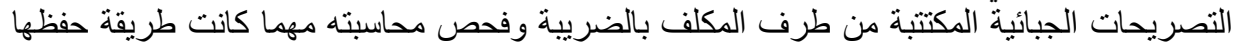

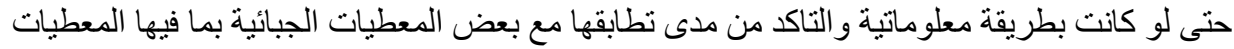

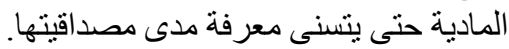

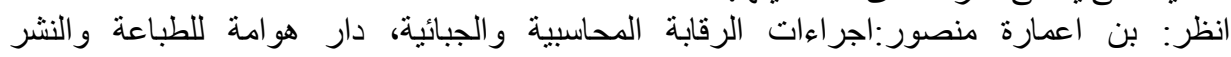

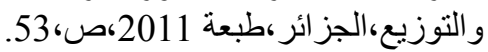

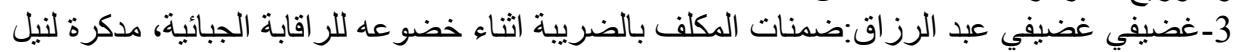

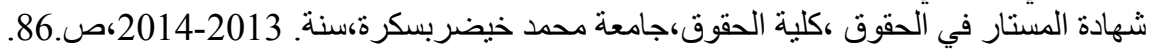

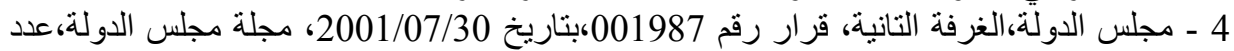
خاص بالمناز عات الضريبية،سنة النة 5 - مجلس الدولة،الغرفة التانية، قرار رقم 009745،بتاريخ 2003 2003/11/18، غير منشور . 6- T.DRIRA : la vérification fiscale.Mémoire de DEA.en droit des affaires. fds. 2002-2003.p.45.

7- N.BACCOUCHE : de la nécessite du control fiscale.RTF.N.12004.P.25.

8- j.SCHMIDT :le controle des activites professionnelles.in.l amelioration des rapports entre 1 adminstration fiscale et le contribuable.actes du colloque organise a orleans.15-16sbtembre1988.p13.

09-احمدفنديس: ضمنات المكلف بالضريبة الخاضع للتدقيق الضريبية، مجلة التواصل في الاقتصاد

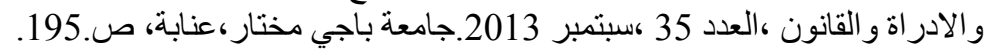
10- FERIEL Kammoun :la prouve en matiere fiscale. Mémoire DEA .faculte du droit de sfax.2001-2002.p.

11- MOUHAMED KOSSENTINI : les garanties du contribuable lors de la vérification fiscal article.p.311.

12- O.GADHOUM :Linsuffisance de la protection du contribuable lors du contrôle fiscale. Mémoire de DEA en droit des affaires.FDS.1997.P.67.

13- MOUHAMED. KOSSENTINI :les garanties du contribuable lors de la vérification fiscal .OP.CIT.P312. 